\title{
Neue Arten von Irpex und Polyporus.
}

\author{
Von \\ Atsushi Yasuda, Rigakushi. \\ Dozent der Botanik an der Tōhoku Kaiserlichen Universität zu Sendai; \\ Professor der Zweiten Hochschule. \\ Mit 3 Textfiguren.

\section{Irpex paryulus YASUdA. ${ }^{1)}$}

Fruchtkörper umgewendet, ausgebreitet, zurückgebogen, oft weithin krustenförmige Ueberzüge bildend, $0,5-13 \mathrm{~cm}$ breit, dünn, lederartig, oberseits angedrückt faserig, konzentrisch gezont, schmutzig-weiss. Innere Substanz sehr dünn, 0,2-0,3 mm dick, weiss. Zähne sehr klein, dicht stehend, flach, spitz oder eingeschnitten, oft handförmig geteilt, 0,4-0,7 $\mathrm{mm}$ lang, 0,12-0,4 $\mathrm{mm}$ breit, bräunlich. Hymenium mit keulenförmigen, dickwandigen, körnigen, farblosen, 35-40 $\mu$ langen, 6-8 $\mu$ breiten Zystiden besetzt. Sporen elliptisch, glatt, farblos, 4-5 $\mu$ lang, 3-3,5 $\mu$ breit.

Nom. Jap. Kogòme-usuba-take.

Hab. An Stämmen voń Quercus glandulifera BL., Quercus crispula BL., Amelanchier asiatica EndL., Fraxinus longicuspis Sier. et Zucc. und Lespedeza Buergeri Mro. Sendai, Prov. Rikuzen; 1. Okt. 1916 (A. Y YASUdA). An Baumstämmen. Berg Miktıma, Sumoto-machi, Tsuna-gōri, Prov. Awaji; 3. Nov. 1916 (S. Matsuzawa). Berg Kasagata, Kansaki-gōri, Prov. Harima ; 28. Dez. 1916 (K. MAtsushima). Otomo-mura, Kesen-göri, Prov. Rikuzen ; 7. Nov. 1920 (G. Това). Shiogama-machi, Miyagi-göri, Prov. Kikuzen; 5. Juni 1921 (S. DaIGo). Berg Tsukikuma, Kita-mameda, Hita-machi, Hita-gōri, Prov. Bungo ; 24. Feb. 1921 (N. Nakayama).

1) Vergl. A. YASUdA, Notes on Fungi (116). Botan. Magaz. Tokyo, Vol. XXXV, No. 419, p. 254. 


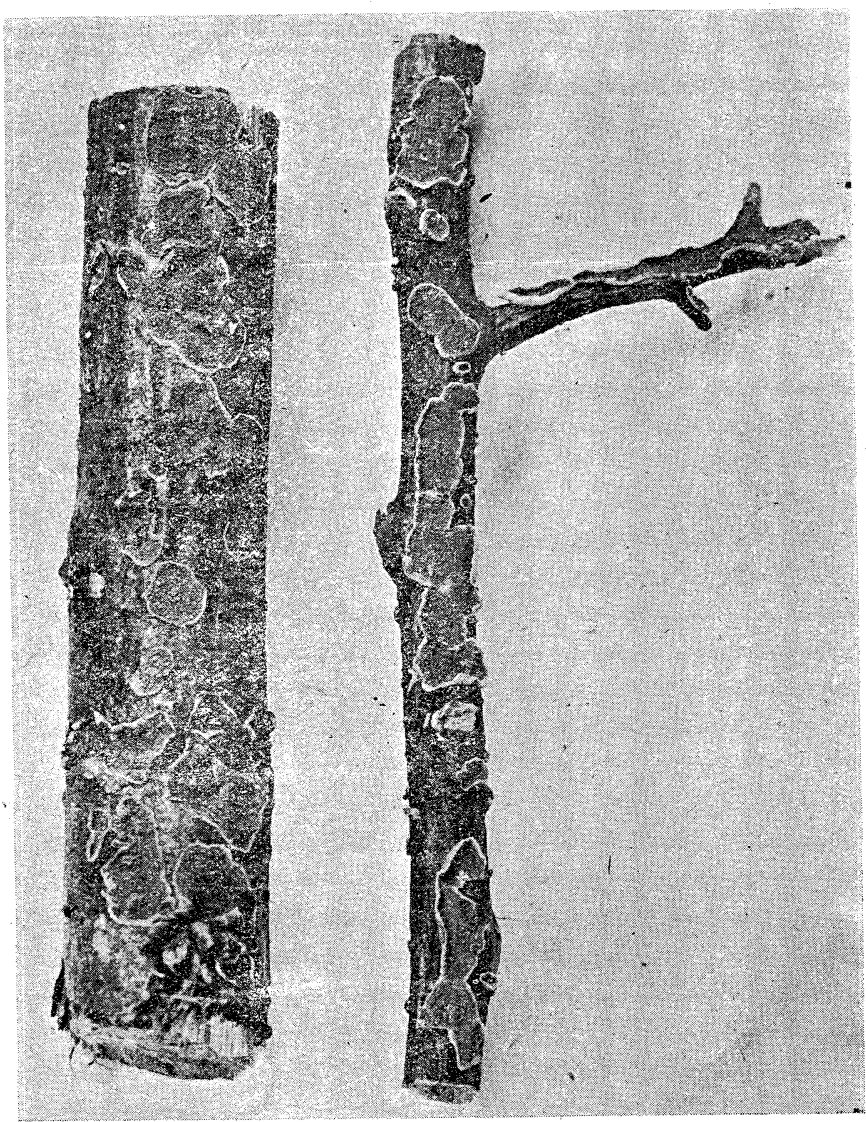

Fig. 1.

Fig. 1. Irpex parvulus YASUDA. Habitusbild. Nat. Gr.

\section{Polyporus Kanehirae Yasuda. ${ }^{1)}$}

Hut sitzend, fächerförmig, dachziegelförmig übereinander, am Hinterende verschmälert, ziemlich dünn, korkig-holzig, 4-8 cm lang, 4-11 cm breit, 4-9 mm dick, oberseits flach-gewölbt, filzig, dicht konzentrisch gezont, braun, im Alter graubraun werdend. Innere Substanz kastanienbraun. Röhren 2-4 mm lang, braun, mit kleinen,

1) Vergl. A. Yasuda, Notes on Fungi (113). Botan. Magaz. Tokyo, Vol. XXXV, No. 416, p. 205. 
cckigen, kastanienbraunen Mündungen. Hymenium mit zugespitzten, geraden oder gekrümmten, dickwandigen, braunen, 20-30 $\mu$ langen, 8-15 $\mu$ breiten Zystiden besetzt. Sporen fast kugelig, glatt, gelbbräunlich, 2,5-3 $\mu$ im Durchmesser.

Nom. Jap. Yura-take.

Hab. An Baumstämmen. Berg Yưra, Shinchiku-chō, Formosa; 3. April 1918 (R. Kanehira).

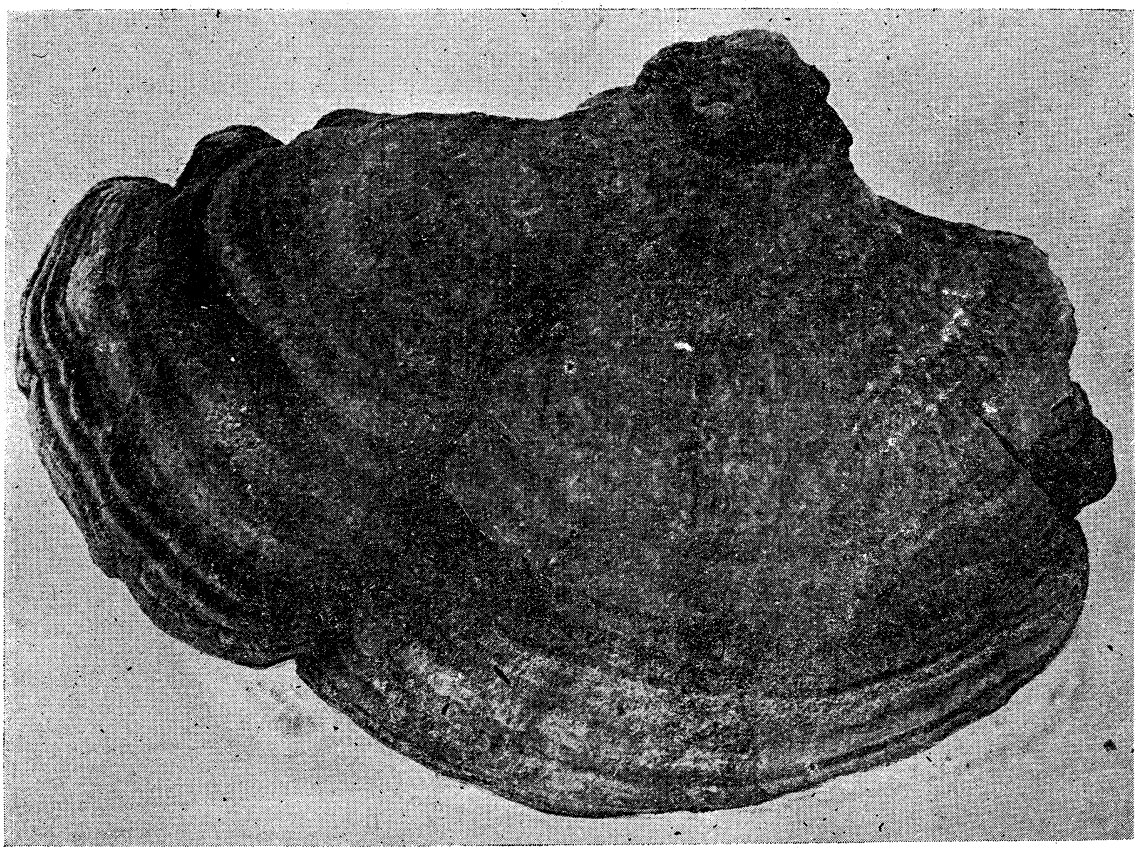

Fig. 2.

Fig. 2. Polyporus Kanehirae Yasuda. Habitusbild. Nat. Gr.

Von oben gesehen.

Dieser Pilz ist durch die kastanienbraune Hutsubstanz, die uns an diejenige von Fomes applanatus (Pers.) Wallr. oder Fomes leucophaeus Mont. erinnert, und durch die gelbbräunlichen Sporen charakterisiert.

Ich habe diesem neuen Pilze zum Andenken an den Entdecker desselben seinen Namen KANEHIRA gegeben. 


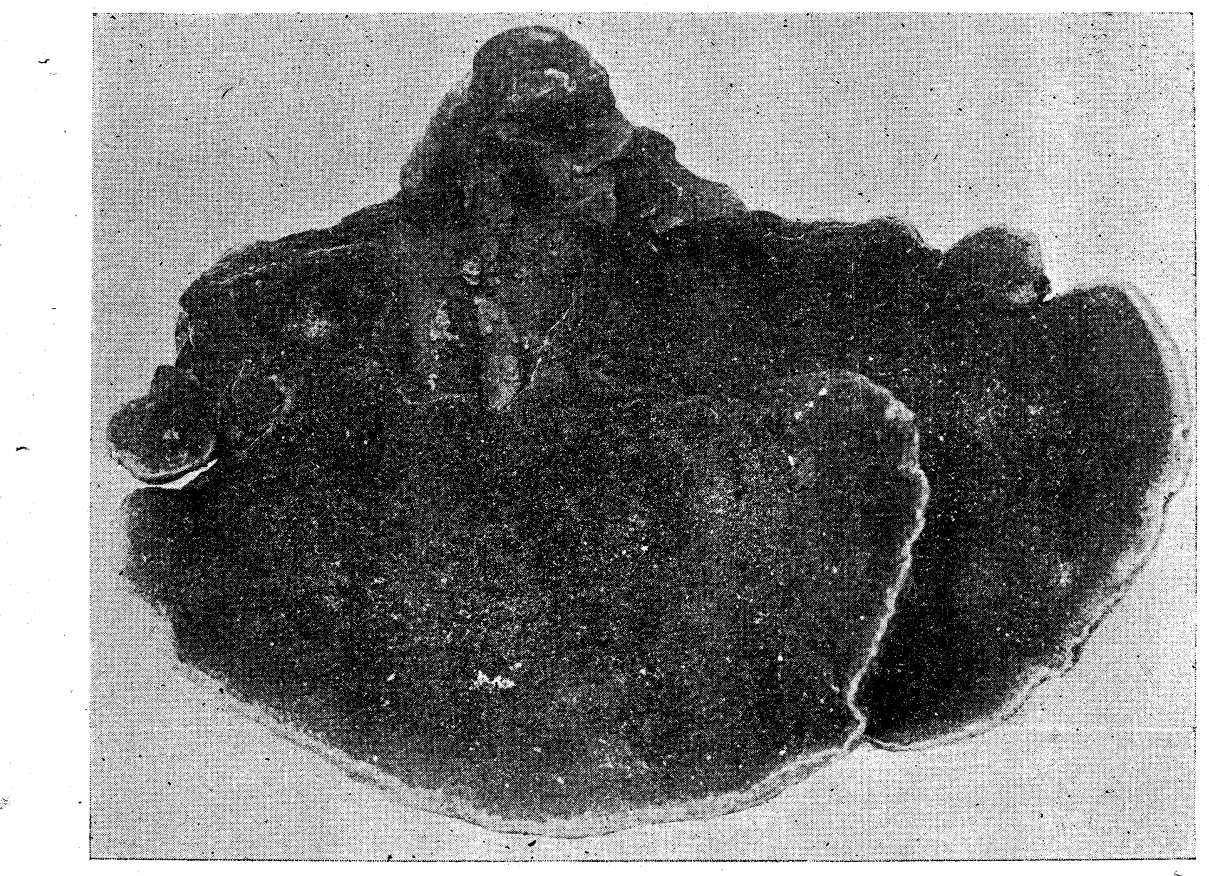

Fig. 3.

Fig. 3. Polyporus Kanehirae Yasuda. Habitusbild. Nat. Gr.

Von unten geschen.

Naturwissenschaftliche Fakultät der Tōhoku Kaiserlichen Universität zu Sendai, 11. Februar 1922. 